Louisiana State University

LSU Digital Commons

Faculty Publications

Department of Biological Sciences

$1-1-2011$

\title{
Virus-derived siRNAs and piRNAs in immunity and pathogenesis
}

Shou Wei Ding

University of California, Riverside

Rui Lu

Louisiana State University

Follow this and additional works at: https://digitalcommons.Isu.edu/biosci_pubs

\section{Recommended Citation}

Ding, S., \& Lu, R. (2011). Virus-derived siRNAs and piRNAs in immunity and pathogenesis. Current Opinion in Virology, 1 (6), 533-544. https://doi.org/10.1016/j.coviro.2011.10.028

This Article is brought to you for free and open access by the Department of Biological Sciences at LSU Digital Commons. It has been accepted for inclusion in Faculty Publications by an authorized administrator of LSU Digital Commons. For more information, please contact ir@lsu.edu. 


\title{
Virus-derived siRNAs and piRNAs in immunity and pathogenesis
}

\author{
Shou-Wei Ding ${ }^{1}$ and Rui Lu \\ ${ }^{1}$ Department of Plant Pathology \& Microbiology, and Institute for Integrative Genome Biology, \\ University of California, Riverside, CA 92521 \\ ${ }^{2}$ Department of Biological Sciences, Louisiana State University, Baton Rouge, LA 70803
}

\section{Abstract}

Cellular organisms have evolved related pathways for the biogenesis and function of small interfering RNAs (siRNAs), microRNAs and PIWI-interacting RNAs (piRNAs). These distinct classes of small RNAs guide specific gene silencing at both transcriptional and posttranscriptional levels by serving as specificity determinants. Small RNAs of virus and host origins have been found to modulate virus-host interactions by RNA interference (RNAi), leading to antiviral immunity or viral pathogenesis. Deep sequencing-based profiling of virus-derived small RNAs as products of host immune recognition not only allowed us to gain insight into the expansion and functional specialization of host factors involved in the antiviral immunity, but also made it possible to identify new viruses in a culture-independent manner. Here we review recent developments on the characterization and function of virus-derived siRNAs and piRNAs in eukaryotic hosts.

\section{Introduction}

Small RNAs determine specificity in RNA silencing or RNA interference (RNAi) by recognizing complementary RNA and DNA targets [1-3]. These small RNAs are products of distinct biogenesis pathways and include small interfering RNAs (siRNAs), microRNAs (miRNAs) and PIWI-interacting RNAs (piRNAs). Both siRNAs and miRNAs are 20 to 24 nucleotides in length and are produced by the dsRNA-specific Dicer nucleases whereas piRNAs are longer (23 to $30 \mathrm{nt}$ ) and Dicer-independent. However, siRNAs, miRNAs and piRNAs all load into Argonaute proteins (AGOs) to mediate RNA cleavage, translational repression, RNA destabilization or epigenetic modifications to the histones or DNA. Accumulating evidence suggested specificity of distinct AGO proteins in binding small RNAs according to their duplex structure and the identity of their first nucleotide [1-3].

In addition to Dicer and AGO proteins, several families of proteins contribute to the biogenesis and function of small RNAs [1-3]. These include the family of dsRNA-binding proteins with tandem dsRNA-binding domains (e.g., RDE-4, R2D2 and TRBP) required for the biogenesis and/or AGO loading of small RNAs by direct interactions with the Dicer family of type III ribonucleases. RNA silencing in fungi, plants and nematodes depends on the amplification of siRNAs by cellular RNA-dependent RNA polymerases (RdRP) found also in ticks, but not in fruit flies, mosquitoes or mammals. In addition, RNA helicases (e.g.,

(C) 2011 Elsevier B.V. All rights reserved.

Correspondence: shou-wei.ding@ucr.edu; ruilu@1su.edu.

Publisher's Disclaimer: This is a PDF file of an unedited manuscript that has been accepted for publication. As a service to our customers we are providing this early version of the manuscript. The manuscript will undergo copyediting, typesetting, and review of the resulting proof before it is published in its final citable form. Please note that during the production process errors may be discovered which could affect the content, and all legal disclaimers that apply to the journal pertain. 
SDE-3, Armitage and DRH-1) play important roles in diverse small RNA pathways, although the molecular mechanism underlying the biological function of these RNA helicases remains largely unknown. Moreover, the steady state accumulation, therefore the function, of small RNAs is also influenced by other host factors that regulate the small RNA metabolism.

Virus infection induces the production of virus-derived small RNAs (vsRNAs) with properties of siRNAs [4-6], miRNAs [7] and/or piRNAs [8] in diverse eukaryotic organisms. These viral small RNAs modulate a wide spectrum of virus-host interactions, leading to the establishment of antiviral immunity or development of viral disease. As recently reviewed comprehensively [9-12], viral siRNAs processed from dsRNA replicative intermediates guide specific antiviral immunity by RNAi in fungi, plants and invertebrates (Fig. 1) and herpesviral miRNAs modulate pathogenicity and immune responses in mammals. It is important to point out that fruit fly mutants (e.g., dicer-2 and $r 2 d 2 \mathrm{RNAi}$ defective mutants) severely defective in antiviral immunity are not compromised in bacterial immunity by Toll and Imd signaling pathways and that direct proof of either production or antiviral activity of viral siRNAs in mammalian cells has yet been demonstrated. In this article, we will review the new developments on the siRNA-directed antiviral immunity and highlight the recent discoveries of vsRNAs in mammalian hosts and viral piRNAs in insect cells as well as the application of vsRNA deep sequencing in culture-independent virus discovery.

\section{Small RNAs derived from hepatitis $C$ and influenza $A$ viruses}

Infection of mammalian hosts with several families of nucleus-replicating DNA viruses triggers production of viral miRNAs [7,12]. However, there has been no direct evidence of production of viral siRNAs in mammalian cells infected with RNA viruses, unlike in fungi, plants and invertebrates [9-11]. Use of deep sequencing platforms in a recent study revealed low abundant vsRNAs in mammalian cells infected with several positive-strand RNA viruses exhibiting key features of viral siRNAs [6]. For example, vsRNAs from hepatitis C virus (HCV) and poliovirus have approximately equal strand ratios and contain paired strands with 2-nt 3' overhangs, suggesting that these vsRNAs are Dicer products processed from a dsRNA precursor. Moreover, co-immunoprecipitation demonstrated loading of $\mathrm{HCV}$ vsRNAs into human Argonaute proteins [6]. However, it is unknown why these vsRNAs do not exhibit a size preference as expected for siRNAs or piRNAs, which have been found in Drosophila (Fig. 2), and if they mediate specific silencing of viral RNAs in the infected mammalian cells. It also remains to be determined if similar siRNA-like vsRNAs are produced in mammalian cells in response to infection of other related and unrelated RNA viruses.

Profiling small RNAs in mammalian cells infected with influenza A virus identified an unusual class of vsRNAs $[13,14]$. These vsRNAs correspond to the precise $5^{\prime}$ ends of all eight segments of the viral negative-strand genomic RNA (vRNA), exhibit random size distribution within the range of 18-27 nt because of their heterogeneous $3^{\prime}$ ends, and accumulate to levels readily detectable by Northern blots 2 to 8 hours post infection [13,14]. In contrast to AGO-loaded mammalian miRNAs and siRNAs that contain 5' monophosphate, the influenza vsRNAs bear a 5'-terminal triphosphate and physically associate with the viral RdRP complex [13]. Therefore, the influenza vsRNAs may result from either premature termination during vRNA synthesis by the viral RdRP or non-specific endonucleolytic cleavages of vRNA.

These influenza vsRNAs were referred as leader RNAs (leRNAs) similar to the short leader RNAs derived from the 5' ends of the genomic RNA of several negative-strand RNA viruses 
such as vesicular stomatitis virus (VSV) [14]. The VSV leRNAs range from 44 to $54 \mathrm{nt}$ in length and have been proposed to regulate the switch from mRNA transcription to genomic RNA replication. Consistent with a regulatory role, the influenza vsRNAs do not induce the autonomous antiviral defense responses in mammalian cells [13]. Notably, introduction of a locked nucleic acid (LNA) complementary to the segment 4 leRNA specifically inhibited the accumulation of the segment vRNA in single-cycle infection assays, but had little effect on the accumulation of either the complementary vRNA (cRNA) or the mRNA from segment 4 [13]. Since LNA treatment is expected to deplete the complementary leRNA as shown for miRNA-complementary LNAs, this finding suggests a role for leRNA in the virus genome replication [13]. However, additional studies are necessary to establish the specificity of the LNA oligo because the segment 4 vRNA, unlike its positive-strand cRNA or mRNA, also has the potential to bind to the LNA oligo.

\section{How potent is the insect RNA-based immunity?}

Infection of Drosophila with positive-, negative- and double-strand RNA viruses induces Dicer2-dependent production of viral siRNAs, which are predominantly 21-nt in length with approximately equal strand ratios (Fig. 2A) and load into AGO2 (reviewed in $[9,10]$ ). Specific AGO2-dependent silencing guided by viral siRNAs has been recently detected in Drosophila cells infected with VSV [15]. This finding supports the earlier genetic studies showing that active dicing to produce viral siRNAs without AGO2-dependent slicing in mutant Drosophila cells, embryos or flies is insufficient to suppress virus replication $[9,10]$.

Viral suppressors of RNA silencing (VSRs) B2 and A1 encoded by members in the Nodaviridae and Dicistroviridae respectively act by distinct mechanisms [9, 16-18]. Viruses from both families contain a positive-strand RNA genome. A1 is translated directly from the genomic RNA as a polyprotein and proteolytically cleaved from the $\mathrm{N}$-terminal region. In contrast, B2 expression depends on the production of the subgenomic RNA from RNA1 of the bipartite nodaviral genome, which self-replicates independently of RNA2 since it also encodes the viral RdRP (Fig. 3, top right) [19]. B2-deficient mutant RNA1 (R1 $\Delta \mathrm{B} 2)$ of Flock house virus (FHV) and Nodamura virus (NoV) fails to replicate to detectable levels in cultured Drosophila and mosquito cells so that $\mathrm{AGO} 2$ depletion is required for rescue of $\mathrm{R} 1 \triangle \mathrm{B} 2$ accumulation $[5,20]$. Similarly, either $\mathrm{B} 2$ expression or presence of a loss-offunction allele in DCR2 or AGO2 is essential to ensure robust replication of FHV RNA1 in Drosophila embryos or transgenic flies [5,21,22]. Recent studies have further shown that heterologous expression of B2 and A1 from the genome of Sindbis virus dramatically enhances virus accumulation and virulence in adult mosquitoes and fruit flies, respectively $[18,23]$. Notably, injection of dsRNA targeting $D C R 2$ or $A G O 2$ increased replication of Dengue virus-2 (DENV2) in the mosquito vector and decreased the extrinsic incubation period required for virus transmission [24]. These findings together demonstrate that RNAbased immunity plays a major role in insect defense against virus infection, unlike bacterial and fungal immunity that depends on the transcriptional induction of the antimicrobial peptide genes by the closely related Toll and Imd signaling pathways [9].

Virions of the B2-deficient FHV mutant, FHV $\triangle \mathrm{B} 2$, are unable to initiate a productive infection in either Drosophila S2 cells or adult Drosophila [21,25]. However, FHV $\Delta$ B2 replicated to high levels and induced high mortality rates in $d c r 2$ and ago2 mutant flies and FHV $\Delta \mathrm{B} 2$ also efficiently infected $r 2 d 2$ mutant flies [25]. Therefore, RNA-based immunity is sufficiently potent to terminate viral infection in the adult insect so that the virus-encoded VSR activity is essential for establishing infection. These findings suggest that as is known for plant viruses [26,27], VSRs may constitute an indispensable functional module for viruses that can establish a productive infection in insects. Deep sequencing revealed presence of a low abundant, yet typical population of viral siRNAs in wildtype flies 
accompanying the arrest of FHV $\triangle \mathrm{B} 2$ infection [25]. When RNAi was suppressed, however, viral small RNAs became strongly biased for positive strands at later stages of infection [25]. This suggests that degradation of the asymmetrically produced viral positive-strand RNAs associated with abundant virus accumulation may contribute to the positive-strand bias of viral small RNAs.

\section{A new small animal model for viral immunity and pathogenesis}

Caenorhabditis elegans has served as a genetically tractable model organism for studying many aspects of biology, including host responses to bacterial pathogens [28]. It grows on agar plates with Escherichia coli lawns as a food source, has a 3-day life cycle with a transparent body, produces $\sim 300$ progeny from each animal, and is often the most popular animal species for whole genome forward genetic screens. In addition to the classical mutagenesis protocols, whole genome screens are readily achieved by feeding RNAi (worms are fed with a library of $E$. coli strains expressing dsRNA targeting $C$. elegans genes), which directly identifies the genes without genetic mapping.

The recent discovery of Orsay and Santeuil viruses that naturally infect and cause diseases in C. elegans and C. briggsae respectively [29] has reignited the idea of using worms as a model to study viral immunity and pathogenesis [30-33]. Interestingly, both viruses belong to the Nodaviridae that includes the broad host-range FHV used in one of the first $C$. elegans viral immunity studies [30]. These pioneering worm studies utilized infection of primary cultured cells with VSV or replication of FHV in whole animals launched from an inducible and integrated FHV transgene. The replication cycle of FHV in the transgenic model begins with translation of the viral RdRP in the cytosol from nuclear transcripts and thus bypasses the initial steps in virus entry that occur during infection of worm cells by VSV. However, both viruses are restricted by the same set of RNAi pathway genes such as $r d e-1$ and $r d e-4$ [30-32], indicating that the immunity is triggered by viral RNA replication in the cytoplasm.

Orsay virus readily infected $r d e-1$ and $r d e-4$ mutants and yielded higher levels of viral RNA and visible disease symptoms as compared to the wildtype $\mathrm{N} 2$ strain of $C$. elegans [29].

Moreover, the infected worms produced viral siRNAs as shown by deep sequencing although only the negative-strand vsRNAs have a preferred size of 22-nt [29], in contrast to siRNAs derived from B2-deficient FHV mutant that are predominantly 23-nt in length for both strands [8] (Fig. 3, bottom left). These results demonstrate induction of RNA-based immunity in the infected worms that protects worms from virus infection and are therefore consistent with the early studies [30-32].

Recent construction of a transgenic $C$. elegans strain carrying a modified FHV replicon has facilitated the genetic analysis of the animal antiviral immunity pathways [34]. The B2 gene in FHV RNA1 is removed and replaced with GFP in the replicon, FR1gfp (Fig. 3, top right). B2 removal dramatically sensitizes the viral replicon to host immunity so that intense GFP expression associated with robust viral replication is observed only in mutant worms such as rde- 1 defective in the antiviral immunity pathway [34] (Fig. 3, top left). Use of the FR1gfp worms in a small-scale feeding RNAi screen has identified 35 genes that may play a role in antiviral immunity. The identified genes include many well-characterized RNAi factors as well as $d r h-1$, which is dispensable for RNAi targeting cellular genes and highly homologous to the mammalian RIG-I family of immune receptors for RNA viruses [35-37] (Fig. 3, bottom right). Thus, it is likely that genome-wide genetic screens in the animal model by either feeding RNAi or classical mutagenesis approaches will provide a genomeview of viral immunity genes of $C$. elegans and identify homologous mammalian genes and pathways with an antiviral function. 


\section{Functional expansion and specialization in plants}

RNA-based immunity against RNA viruses in Arabidopsis thaliana is controlled by multiple cooperative siRNA pathways involving two Dicer-like proteins (DCL) and three AGOs in contrast to a single DCR2-AGO2 siRNA pathway in D. melanogaster (reviewed in $[9,10]$ ). In addition, potent antiviral silencing requires amplification of viral siRNAs by either $A$. thaliana RdRP 1 (RDR1) or RDR6 (Fig. 4A), homologs of which are found in fungi, $C$. elegans and ticks, but not in humans or D. melanogaster; an earlier report of the D-elp1 subunit of the Drosophila RNA polymerase II elongation complex as a non-canonical RdRP was recently retracted [38]. Notably, recent studies have revealed functional specialization in different members of DCL, RDR and AGO families by using virus mutants deficient in the expression of the cognate VSR [39-44]. For example, RDR1 and RDR6 appear to target different genomic regions of cucumber mosaic virus (CMV) for siRNA amplification even though either RDR alone is sufficient to confer virus resistance [40,42,43]. Similarly, loss of DCL4 alone partially rescues systemic infection of VSR-defective mutants of CMV, turnip crinkle virus (TCV) and turnip mosaic virus (TuMV), but virulent infection is fully restored only in mutant plants defective for both DCL2 and DCL4 [39,40,42,43].

Both DCL2 and DCL4 appear to have access to the viral dsRNA products of the viral and host RdRPs, leading to production of viral primary and secondary siRNAs, respectively $[40,42,43,45]$. In contrast to DCL4-depedent 21-nt viral siRNAs, however, 22-nt siRNAs produced by DCL2 in response to the CMV mutant, which accumulate to high levels in $d c l 4$ mutant plants, are unable to direct effective antiviral silencing [44]. One hypothesis to explain the qualitative difference is that the longer siRNA does not guide efficient cleavages of the target RNA by RNA-induced silencing complex (RISC). Interestingly, RDR6dependent dsRNA synthesis and subsequent siRNA biogenesis is triggered by the cleavage of the target mRNA guided by 22-nt miRNAs, but not by 21-nt miRNAs [46,47], suggesting a similar qualitative difference between 21- and 22-nt miRNAs.

A recent study also indicates that AGO1 and AGO2 of A. thaliana exhibit unique and cooperative antiviral properties [44]. A. thaliana mutants defective in either AGO1 or AGO2 displayed enhanced virus susceptibility and additive effects between agol and ago 2 mutant alleles were revealed by examining 25 single, double and triple mutants impaired in nine AGO genes $[44,48,49]$. Viral siRNAs including viral secondary siRNAs accumulated to high levels in the infected agol, ago2 and agol ago2 mutant plants and coimmunoprecipitated with AGO1 and AGO2 [44,48] (Fig. 4B). Deep sequencing showed similar enrichment of both 21- and 22-nt viral siRNAs in AGO1 and AGO2. However, approximately $90 \%$ of AGO1- and AGO2-loaded viral siRNAs contain a 5'-terminal U and A, respectively, as found for plant endogenous small RNAs [3]. These findings indicate that AGO1 and AGO2 are both dispensable for the biogenesis of viral siRNAs and may cooperatively cleave viral RNAs guided by two overlapping sets of viral siRNAs (Fig. 4B).

\section{Mechanism of viral disease symptoms}

Three recent papers published by PLOS Pathogens provide some fascinating insights on how virus-host interactions are responsible for the induction of disease symptoms [50-52]. Coinfection of CMV with a 339-nt single-stranded satellite RNA (satRNA) induces a bright yellow leaf symptom in Nicotiana species including $N$. benthamiana plants [53]. satRNA replication by the helper virus triggers massive production of satRNA-derived siRNAs, which unlike the biogenesis of the helper viral siRNAs, does not depend on either RDR1 or RDR6 [42,54,55]. Two groups of investigators now show that the yellow symptom is caused by specific silencing of a host gene encoding the subunit I of magnesium protoporphyrin chelatase (ChlI) involved in chlorophyll biosynthesis, which is mediated by a siRNA derived 
from the previously mapped pathogenicity region of the yellow isolate of satRNA [51,52]. Minimal substitutions introduced into satRNA that disrupted the complementarity with the ChlI mRNA of $N$. benthamiana prevented induction of the yellow symptom (Fig. 5), whereas those substitutions that restored the complementarity with tomato and A. thaliana ChlI mRNAs gained the activity to induce the yellow symptom [51].

Stable expression of VSRs under the control of broad tissue specificity promoters in transgenic plants can interfere with the functionality of endogenous miRNAs and siRNAs and induce severe developmental abnormities similar to disease symptoms (reviewed in [56]). The study by Voinnet and colleagues showed that introduction of a mutant allele for Auxin Response Factor 8 (ARF8), a transcriptional factor targeted by miRNA 167, largely eliminated the developmental abnormities associated with VSR expression in transgenic plants [50]. Notably, leaf serration, which is part of the disease complex induced by TuMV infection in wildtype $A$. thaliana plants, was also hardly discernable in the infected arf8 mutant plants [50]. These findings suggest that VSR-mediated misregulation of host genes targeted by endogenous small RNAs contributes to the development of disease symptoms. It should be pointed out that additional viral factors must play key roles in the induction of viral diseases since VSR-defective TCV, CMV and TuMV mutants are highly virulent in silencing-defective plants [39,40,42,43] (Fig. 4A).

\section{Viral piRNAs from insects}

First viral piRNAs were detected in Drosophila ovarian somatic sheet (OSS) cells persistently infected with six RNA viruses [8] (Fig. 2B). The OSS cells produce typical populations of viral siRNAs targeting four of these viruses, including two positive-strand RNA viruses and two dsRNA viruses. However, the population of 21-nt viral siRNAs is not as predominant for the remaining two positive-strand RNA viruses, Drosophila $\mathrm{C}$ virus (DCV) and American nodavirus (ANV, $\sim 88 \%$ nucleotide sequence identity with FHV). Instead, a distinct population of vsRNAs of 23 to 30 nucleotides in length was more abundant for both DCV and ANV (Fig. 2B). These longer vsRNAs are defined as viral piRNAs because they are almost exclusively in one polarity (Fig. 2B) and have a strong preference for uridine at the $5^{\prime}$ terminus (Fig. 2C), which are the two notable features of the PIWI-loaded endogenous primary piRNAs detected in OSS cells [57,58]. OSS cells are related to ovarian follicle cells that ensheath oocytes and express PIWI, but not AGO3 or Aubergine (AUB), all of which are members from the PIWI subfamily of AGOs conserved in animals but absent in plants [1-3].

Recent deep sequencing studies revealed similar populations of viral piRNAs in the cultured C6/36 mosquito cell line originally derived from embryos of Aedes albopictus mosquitos $[59,60]$. vsRNAs detected in C6/36 mosquito cells mix infected with Dengue virus- 2 (DENV2) and cell fusing agent virus (CFAV, an insect flavirus) are almost exclusively positive strands and predominantly 27 nucleotides in length without an obvious peak at 21nt [59]. This is in contrast to a typical DENV2 siRNA population detected in A. aegypti mosquitoes and Aag2 cell culture infected with DENV2. Interestingly, the longer vsRNAs of DENV2 and CFAV from C6/36 cells exhibit a modest preference for A at nucleotide position 10, a feature of AGO3-loaded piRNAs in Drosophila [1,2]. vsRNAs in the size range of 23 to 28 nucleotides were also found in C6/36 cells infected with either Sindbis virus or La Crosse virus although further characterization of these vsRNA populations is necessary to determine if these longer vsRNAs have preferences for a 5'-terminal $\mathrm{U}$ or for A at nucleotide position 10 [60].

Detection of viral piRNAs in insect cells suggests an antiviral role for the piRNA pathway, which may represent a distinct functional specialization of RNA silencing specific to 
animals. This hypothesis is consistent with the early observations that piwi and aub Drosophila mutants exhibit enhanced virus susceptibility [61,62]. However, piRNA pathway mainly acts to repress transposons and repeat elements in the germline which RNA viruses often do not invade with a few exceptions [63]. Does this suggest a role for the piRNA pathway to prevent viral invasion into the germline and to inhibit viral vertical transmission, or in antiviral defense in the soma? In addition, the viral piRNAs detected in Drosophila and mosquito cells are mostly positive strands. These viral piRNAs are not expected to target the viral positive-strand viral genomic RNA and mRNA although processing the viral RNAs into piRNAs itself may be antiviral. Future studies in adult flies and mosquitoes will be necessary to determine if viral antisense piRNAs are produced and if the piRNA pathway have an antiviral role in the soma and germline.

\section{Virus discovery by deep sequencing and assembly of vsRNAs}

The first reported deep sequencing study of vsRNAs showed surprisingly that viral siRNAs produced by the host immune system overlap in sequence [21], in contrast to plant endogenous trans-acting siRNAs and Drosophila hairpin RNA transgene-derived siRNAs that are in 21-nt phases [1-3, 64-65]. Subsequent studies found that Dicer cleavage may occur at every nucleotide position of the replicating viral genome and that viral piRNAs also overlap [8, 66-68]. Based on this overlapping feature of vsRNAs, a novel cultureindependent approach for virus discovery has been developed and termed vdSAR for virus discovery by deep sequencing and assembly of total small RNAs $[8,69]$.

In vdSAR (Fig. 6A), total small RNAs were isolated from a host, sequenced in a single Illumina lane, and assembled into contigs by the Velvet program developed for genome assembly from short reads. Virus-specific contigs are identified by searching the nonredundant nucleotide sequence entries of NCBI both before and after in silico translation using BlastN and BlastX, respectively. The complete genomes of the viruses identified could subsequently be recovered by PCR and cloned. Use of vdSAR led to the discovery of two new geminiviruses from sweet potato and five new positive-strand RNA and dsRNA viruses from Drosophila and mosquitoes $[8,69]$. Notably, four of the identified invertebrate viruses exhibit only low sequence similarities to known viruses so that none could be assigned into an existing virus genus (Fig. 6B). Thus, vdSAR is capable of discovering new viruses that are only distantly related to known viruses similar to metagenomic approaches used for discovery of viruses in environmental and clinical samples [70].

Metagenomic approaches require partial purification of viral particles and random amplification of viral nucleic acid sequences prior to sequencing. Importantly, vdSAR involves sequencing of the fraction of host small RNAs and data mining of only those small RNAs that can assemble into contigs so that both the amount of sequencing and data complexity are greatly reduced. Importantly, vdSAR identifies only replicating viruses since it assembles viral genomes from the products of an active host immune response to infection. However, neither approach is capable of discovering complete novel viruses that exhibit no detectable homology to known viruses, which represents a major challenge in virus discovery [70].

\section{Concluding remarks}

Viral siRNAs processed from virus-derived dsRNA direct specific clearance of the invading viral RNAs by RNA silencing in fungi, plants and invertebrates. Consistent with previous studies in insect cell culture and in whole plants, a recent study shows that in the absence of a virus-encoded activity to suppress RNAi, RNA-based immunity induced by viral RNA replication is sufficiently potent to terminate infection in adult fruit flies. Importantly, this major antiviral immunity in Drosophila is independent of the Toll and Imd signaling 
pathways essential for bacterial and fungal immunity [37, 71-72]. RNA-based immunity appears less potent in adult female mosquitoes where arthropod-borne RNA viruses replicate to high levels even though they may not encode a VSR. However, RNA silencing inhibits the accumulation of arboviruses in mosquitoes and increases the extrinsic incubation time required for their transmission to the vertebrate hosts.

SiRNA-mediated resistance to RNA viruses in plants is controlled by at least two members of the Dicer, AGO and RdRP protein families. Recent genetic studies further indicate functional diversification in antiviral defense for different Dicer, AGO and RdRP proteins of A. thaliana. For example, 21-nt viral siRNAs produced by DCL4 is much more potent in defense than 22-nt viral siRNAs processed by DCL2 whereas AGO1 and AGO2 act cooperatively by loading distinct sets of viral siRNAs with 5'-ternimal U and A, respectively. By contrast, a single siRNA pathway plays an essential role in defense against RNA viruses in D. melanogaster. However, recent detection of viral piRNAs in Drosophila and mosquito cells suggests an alternative approach to expand the antiviral role of small RNAs in animals.

Isolation of RNA viruses that naturally infect $C$. elegans establishes a novel small animal model to explore innate antiviral mechanisms. Use of the high throughput genetic and genomic tools available in this model host may lead to the identification of host factors required for the recognition of virus-derived dsRNA by Dicer, which may occur either in membrane-enclosed compartments where viral replication takes place or after its release from the damaged membrane structures.

Expression of host genes may be altered by VSRs that interfere with host miRNA activities or silenced directly by viral siRNAs (reviewed in [73]). Surprisingly, however, expression of several distinct VSRs contributes to the development of viral disease symptoms by acting on a common miRNA-regulated transcriptional factor of the host. Recent studies also establish a specific role for a pathogen-derived siRNA in the induction of a well-known yellow leaf symptom. Similarly, hepatitis $C$ virus infection requires a host miRNA that binds to the $5^{\prime}$ terminus of the viral genomic RNA with 3' overhanging nucleotides, which may protect the $5^{\prime}$ terminal viral sequences from nucleolytic degradation or from inducing innate immune responses to the RNA terminus [74]. These findings indicate a dual function for RNA silencing in both viral immunity and viral pathogenesis. In this regard, it is interesting to note that RNA-based immunity is not always beneficial to the host. A recent study shows that loss of the RNA silencing machinery is essential to maintain the beneficial killer virus in Saccharomyces cerevisiae [75].

Detection of siRNA-like vsRNAs in mammalian cells suggests a possible antiviral role for the siRNA pathway in mammals, which has been under debate. It will be critical in future studies to establish a mammalian system for virus infection in which there is production of a vsRNA population with a clear length bias expected for the products (siRNA) of Dicer or for piRNAs. Such a system will make it possible to determine if the viral siRNAs or piRNAs are active in directing specific silencing of the complementary RNAs and if the activity of mammalian VSRs identified in exogenous RNAi assays is required for infection [16,26].

\section{Acknowledgments}

Research programs in S.-W. D.'s lab are supported by the National Institutes of Health grants R01 AI052447 and GM094396, and the California Citrus Research Board. R. L.'s research is currently receiving support from the Board of Regents, Louisiana. 


\section{References}

* of special interest

** of outstanding interest

1. Siomi MC, Sato K, Pezic D, Aravin AA. PIWI-interacting small RNAs: the vanguard of genome defence. Nat Rev Mol Cell Biol. 2011; 12:246-258. [PubMed: 21427766]

2. Kim VN, Han J, Siomi MC. Biogenesis of small RNAs in animals. Nat Rev Mol Cell Biol. 2009; 10:126-139. [PubMed: 19165215]

3. Chen X. Small RNAs and their roles in plant development. Annu Rev Cell Dev Biol. 2009; 25:2144. [PubMed: 19575669]

4. Hamilton AJ, Baulcombe DC. A species of small antisense RNA in posttranscriptional gene silencing in plants. Science. 1999; 286:950-952. [PubMed: 10542148]

5. Li HW, Li WX, Ding SW. Induction and suppression of RNA silencing by an animal virus. Science. 2002; 296:1319-1321. [PubMed: 12016316]

6**. Parameswaran P, Sklan E, Wilkins C, Burgon T, Samuel MA, Lu R, Ansel KM, Heissmeyer V, Einav S, Jackson W, et al. Six RNA viruses and forty-one hosts: viral small RNAs and modulation of small RNA repertoires in vertebrate and invertebrate systems. PLoS Pathog. 2010; 6:e1000764. Changes in viral small RNA (vsRNA) populations during infection of animal cells by six different viruses were characterized through deep sequencing. Populations of vsRNAs with siRNAs characteristics were observed and, in some cases, the abundances of vsRNAs were modulated by the RNAi and interferon pathways. Strand-selective loading of viral siRNAs onto Argonaute complexes was also observed in this study. [PubMed: 20169186]

7. Pfeffer S, Zavolan M, Grasser FA, Chien M, Russo JJ, Ju J, John B, Enright AJ, Marks D, Sander C, et al. Identification of virus-encoded microRNAs. Science. 2004; 304:734-736. [PubMed: 15118162]

8**. Wu Q, Luo Y, Lu R, Lau N, Lai EC, Li WX, Ding SW. Virus discovery by deep sequencing and assembly of virus-derived small silencing RNAs. Proc Natl Acad Sci U S A. 2010; 107:16061611. Five new RNA viruses from cultured Drosophila cells and adult mosquitoes were discovered through assembly of small RNAs sequences in published libraries. Importantly, this study also detected virus-derived piRNAs in Drosophila, which can also be used for virus discovery. This study not only demonstrated a novel virus discovery strategy but also suggested an antiviral function for PIWI subfamily of Argonaute proteins. [PubMed: 20080648]

9. Ding S-W. RNA-based antiviral immunity. Nat Rev Immunol. 2010; 10:632-644. [PubMed: 20706278]

10. Sabin LR, Hanna SL, Cherry S. Innate antiviral immunity in Drosophila. Curr Opin Immunol. 2010; 22:4-9. [PubMed: 20137906]

11. Qu F. Antiviral role of plant-encoded rna-dependent RNA polymerases revisited with deep sequencing of small interfering RNAs of virus origin. Mol Plant Microbe Interact. 2010; 23:12481252. [PubMed: 20831405]

12. Cullen BR. Herpesvirus microRNAs: phenotypes and functions. Curr Opin Virol. 2011; 1:211215. [PubMed: 21927637]

13**. Perez JT, Varble A, Sachidanandam R, Zlatev I, Manoharan M, Garcia-Sastre A, tenOever BR. Influenza A virus-generated small RNAs regulate the switch from transcription to replication. Proc Natl Acad Sci U S A. 2010; 107:11525-11530. This paper and Umbach et al (2010) report production of virus-derived small RNAs 18- to 27-nt that originate from the precise $5^{\prime}$ ends of all eight influenza A virus genomic RNA segments and bear a 5'-terminal triphosphate. [PubMed: 20534471]

14**. Umbach JL, Yen HL, Poon LL, Cullen BR. Influenza A virus expresses high levels of an unusual class of small viral leader RNAs in infected cells. MBio. 2010; 1 This paper and Perez et al (2010) report production of virus-derived small RNAs 18- to 27-nt that originate from the precise 5 ' ends of all eight influenza A virus genomic RNA segments and bear a 5'-terminal triphosphate. 
15. Mueller S, Gausson V, Vodovar N, Deddouche S, Troxler L, Perot J, Pfeffer S, Hoffmann JA, Saleh M-C, Imler J-L. RNAi-mediated immunity provides strong protection against the negativestrand RNA vesicular stomatitis virus in Drosophila. Proceedings of the National Academy of Sciences. 2010

16. Wu Q, Wang X, Ding SW. Viral suppressors of RNA-based viral immunity: host targets. Cell Host Microbe. 2010; 8:12-15. [PubMed: 20638637]

17. Qi N, Cai D, Qiu Y, Xie J, Wang Z, Si J, Zhang J, Zhou X, Hu Y. RNA binding by a novel helical fold of $\mathrm{b} 2$ protein from wuhan nodavirus mediates the suppression of RNA interference and promotes b2 dimerization. J Virol. 2011; 85:9543-9554. [PubMed: 21734038]

18**. Nayak A, Berry B, Tassetto M, Kunitomi M, Acevedo A, Deng C, Krutchinsky A, Gross J, Antoniewski C, Andino R. Cricket paralysis virus antagonizes Argonaute 2 to modulate antiviral defense in Drosophila. Nat Struct Mol Biol. 2010 advance online publication. This study showed that closely related insect viruses, Drosophila $\mathrm{C}$ virus (DCV) and Cricket paralysis virus (CrPV), use distinct mechanisms to suppress host RNAi antiviral defense and that CrPV suppressor protein A1 targets AGO2.

19. Venter PA, Schneemann A. Recent insights into the biology and biomedical applications of Flock House virus. Cell Mol Life Sci. 2008

20. Li WX, Li H, Lu R, Li F, Dus M, Atkinson P, Brydon EW, Johnson KL, Garcia-Sastre A, Ball LA, et al. Interferon antagonist proteins of influenza and vaccinia viruses are suppressors of RNA silencing. Proc Natl Acad Sci U S A. 2004; 101:1350-1355. [PubMed: 14745017]

21. Aliyari R, Wu Q, Li HW, Wang XH, Li F, Green LD, Han CS, Li WX, Ding SW. Mechanism of induction and suppression of antiviral immunity directed by virus-derived small RNAs in Drosophila. Cell Host Microbe. 2008; 4:387-397. [PubMed: 18854242]

22. Galiana-Arnoux D, Dostert C, Schneemann A, Hoffmann JA, Imler JL. Essential function in vivo for Dicer-2 in host defense against RNA viruses in drosophila. Nat Immunol. 2006; 7:590-597. [PubMed: 16554838]

23. Myles KM, Wiley MR, Morazzani EM, Adelman ZN. Alphavirus-derived small RNAs modulate pathogenesis in disease vector mosquitoes. Proc Natl Acad Sci U S A. 2008; 105:19938-19943. [PubMed: 19047642]

24*. Sanchez-Vargas I, Scott JC, Poole-Smith BK, Franz AW, Barbosa-Solomieu V, Wilusz J, Olson KE, Blair CD. Dengue virus type 2 infections of Aedes aegypti are modulated by the mosquito's RNA interference pathway. PLoS Pathog. 2009; 5:e1000299. This study demonstrated accumulation of viral siRNAs in Ae. Aegypti mosquitoes persistently infected with dengue virus type 2 (DENV2) via blood feeding. Notably, depletion of mosquito Dicer-2 or AGO-2 led to an increase in virus replication and a decrease in the extrinsic incubation period required for virus transmission, indicating modulation of virus transmission by RNAi in the arthropod vector. [PubMed: 19214215]

25. Han YH, Luo YJ, Wu Q, Jovel J, Wang XH, Aliyari R, Han C, Li WX, Ding SW. RNA-based immunity terminates viral infection in adult Drosophila in absence of viral suppression of RNAi: Characterization of viral siRNA populations in wildtype and mutant flies. J Virol. published online ahead of print on 28 September 2011. 10.1128/JVI.05518-11

26. Li F, Ding SW. Virus counterdefense: diverse strategies for evading the RNA-silencing immunity. Annu Rev Microbiol. 2006; 60:503-531. [PubMed: 16768647]

27. Burgyan J, Havelda Z. Viral suppressors of RNA silencing. Trends Plant Sci. 2011; 16:265-272. [PubMed: 21439890]

28. Irazoqui JE, Urbach JM, Ausubel FM. Evolution of host innate defence: insights from Caenorhabditis elegans and primitive invertebrates. Nat Rev Immunol. 2010; 10:47-58. [PubMed: 20029447]

29**. Félix M-A, Ashe A, Piffaretti J, Wu G, Nuez I, Bélicard T, Jiang Y, Zhao G, Franz CJ, Goldstein LD, et al. Natural and Experimental Infection of Caenorhabditis Nematodes by Novel Viruses Related to Nodaviruses. PLoS Biol. 2011; 9:e1000586. Two novel RNA viruses distantly related to Nodaviruses were found to naturally and specifically infect C. elegans (Orsay virus) and C. briggsae (Santeuil virus), respectively. Both viruses feature horizontal transmission and the infected animals continuously maintained viral infection across generations in lab. Importantly, Orsay virus readily infected laboratory C. elegans mutants defective in RNAi and 
yielded higher levels of viral RNA and obvious disease symptoms as compared to infection of the corresponding wild-type N2 strain, demonstrating a antiviral role for RNAi in worms. [PubMed: 21283608]

30. Lu R, Maduro M, Li F, Li HW, Broitman-Maduro G, Li WX, Ding SW. Animal virus replication and RNAi-mediated antiviral silencing in Caenorhabditis elegans. Nature. 2005; 436:1040-1043. [PubMed: 16107851]

31. Wilkins C, Dishongh R, Moore SC, Whitt MA, Chow M, Machaca K. RNA interference is an antiviral defence mechanism in Caenorhabditis elegans. Nature. 2005; 436:1044-1047. [PubMed: 16107852]

32. Schott DH, Cureton DK, Whelan SP, Hunter CP. An antiviral role for the RNA interference machinery in Caenorhabditis elegans. Proc Natl Acad Sci U S A. 2005; 102:18420-18424. [PubMed: 16339901]

33. Liu WH, Lin YL, Wang JP, Liou W, Hou RF, Wu YC, Liao CL. Restriction of vaccinia virus replication by a ced-3 and ced-4-dependent pathway in Caenorhabditis elegans. Proc Natl Acad Sci U S A. 2006; 103:4174-4179. [PubMed: 16537504]

34. Lu R, Yigit E, Li WX, Ding SW. An RIG-I-Like RNA helicase mediates antiviral RNAi downstream of viral siRNA biogenesis in Caenorhabditis elegans. PLoS Pathog. 2009; 5:e1000286. [PubMed: 19197349]

35. Rehwinkel J, Reis e Sousa C. RIGorous detection: exposing virus through RNA sensing. Science. 2010; 327:284-286. [PubMed: 20075242]

36. Yoneyama M, Fujita T. RNA recognition and signal transduction by RIG-I-like receptors. Immunol Rev. 2009; 227:54-65. [PubMed: 19120475]

37. Takeuchi O, Akira S. Innate immunity to virus infection. Immunol Rev. 2009; 227:75-86. [PubMed: 19120477]

38. Lipardi C, Paterson BM. Retraction. Proc Natl Acad Sci U S A. 2011; 108:15010. [PubMed: 21821790]

39. Deleris A, Gallego-Bartolome J, Bao J, Kasschau KD, Carrington JC, Voinnet O. Hierarchical Action and Inhibition of Plant Dicer-Like Proteins in Antiviral Defense. Science. 2006; 313:6871. [PubMed: 16741077]

40. Diaz-Pendon JA, Li F, Li WX, Ding SW. Suppression of antiviral silencing by cucumber mosaic virus $2 \mathrm{~b}$ protein in Arabidopsis is associated with drastically reduced accumulation of three classes of viral small interfering RNAs. Plant Cell. 2007; 19:2053-2063. [PubMed: 17586651]

41. Qu F, Ye X, Morris TJ. Arabidopsis DRB4, AGO1, AGO7, and RDR6 participate in a DCL4initiated antiviral RNA silencing pathway negatively regulated by DCL1. Proc Natl Acad Sci U S A. 2008; 105:14732-14737. [PubMed: 18799732]

42**. Wang XB, Wu Q, Ito T, Cillo F, Li WX, Chen X, Yu JL, Ding SW. RNAi-mediated viral immunity requires amplification of virus-derived siRNAs in Arabidopsis thaliana. Proc Natl Acad Sci U S A. 2010; 107:484-489. This paper and Garcia-Ruiz et al (2010) demonstrate an essential role for the amplification of viral siRNAs by host RNA-directed RNA polymerase (RDR) 1 or RDR6 in the defense against two different positive-strand RNA viruses. [PubMed: 19966292]

43**. Garcia-Ruiz H, Takeda A, Chapman EJ, Sullivan CM, Fahlgren N, Brempelis KJ, Carrington JC. Arabidopsis RNA-dependent RNA polymerases and dicer-like proteins in antiviral defense and small interfering RNA biogenesis during Turnip Mosaic Virus infection. Plant Cell. 2010; 22:481-496. This paper and Wang et al (2010) demonstrate an essential role for the amplification of viral siRNAs by host RNA-directed RNA polymerase (RDR) 1 or RDR6 in the defense against two different positive-strand RNA viruses. [PubMed: 20190077]

44**. Wang XB, Jovel J, Udomporn P, Wang Y, Wu Q, Li WX, Gasciolli V, Vaucheret H, Ding SW. The 21-Nucleotide, but Not 22-Nucleotide, Viral Secondary Small Interfering RNAs Direct Potent Antiviral Defense by Two Cooperative Argonautes in Arabidopsis thaliana. Plant Cell. 2011; 23:1625-1638. This work demonstrates cooperative antiviral activities of AGO1 and AGO2 and a qualitative difference between 21- and 22-nucleotide viral siRNAs produced by DCL4 and DCL2, respectively. [PubMed: 21467580] 
45. Donaire L, Barajas D, Martinez-Garcia B, Martinez-Priego L, Pagan I, Llave C. Structural and genetic requirements for the biogenesis of tobacco rattle virus-derived small interfering RNAs. J Virol. 2008; 82:5167-5177. [PubMed: 18353962]

46*. Cuperus JT, Carbonell A, Fahlgren N, Garcia-Ruiz H, Burke RT, Takeda A, Sullivan CM, Gilbert SD, Montgomery TA, Carrington JC. Unique functionality of 22-nt miRNAs in triggering RDR6-dependent siRNA biogenesis from target transcripts in Arabidopsis. Nat Struct Mol Biol. 2010; 17:997-1003. This study and Chen et al demonstrate dsRNA synthesis and siRNA biogenesis following target RNA cleavages guided by 22-nucleotide miRNAs, but not 21nucleotide miRNAs. [PubMed: 20562854]

47*. Chen HM, Chen LT, Patel K, Li YH, Baulcombe DC, Wu SH. 22-Nucleotide RNAs trigger secondary siRNA biogenesis in plants. Proc Natl Acad Sci U S A. 2010; 107:15269-15274. This study and Cuperus et al demonstrate dsRNA synthesis and siRNA biogenesis following target RNA cleavages guided by 22-nucleotide miRNAs, but not 21-nucleotide miRNAs. [PubMed: 20643946]

48. Harvey JJ, Lewsey MG, Patel K, Westwood J, Heimstadt S, Carr JP, Baulcombe DC. An Antiviral Defense Role of AGO2 in Plants. PLoS ONE. 2011; 6:e14639. [PubMed: 21305057]

49. Jaubert M, Bhattacharjee S, Mello AF, Perry KL, Moffett P. ARGONAUTE2 mediates RNAsilencing antiviral defenses against Potato virus X in Arabidopsis. Plant Physiol. 2011; 156:15561564. [PubMed: 21576511]

50**. Jay F, Wang Y, Yu A, Taconnat L, Pelletier S, Colot V, Renou JP, Voinnet O. Misregulation of AUXIN RESPONSE FACTOR 8 underlies the developmental abnormalities caused by three distinct viral silencing suppressors in Arabidopsis. PLoS Pathog. 2011; 7:e1002035. This work indicates a role for the misregulation of a miRNA-targeted host gene by viral suppressors of RNA silencing in the development of viral disease symptoms. [PubMed: 21589905]

51 **. Shimura H, Pantaleo V, Ishihara T, Myojo N, Inaba J-i, Sueda K, Burgyán J, Masuta C. A Viral Satellite RNA Induces Yellow Symptoms on Tobacco by Targeting a Gene Involved in Chlorophyll Biosynthesis using the RNA Silencing Machinery. PLoS Pathog. 2011; 7:e1002021. This study and Smith et al (2011) demonstrate induction of a specific yellow leaf disease symptom by a siRNA derived from the replicating satellite RNA of Cucumber mosaic virus. [PubMed: 21573143]

52**. Smith NA, Eamens AL, Wang M-B. Viral Small Interfering RNAs Target Host Genes to Mediate Disease Symptoms in Plants. PLoS Pathog. 2011; 7:e1002022. This study and Shimura et al (2011) demonstrate induction of a specific yellow leaf disease symptom by a siRNA derived from the replicating satellite RNA of Cucumber mosaic virus. [PubMed: 21573142]

53. Scholthof KB. Taking some of the mystery out of host: virus interactions. PLoS Pathog. 2011; 7:e1002033. [PubMed: 21573135]

54. Fusaro AF, Matthew L, Smith NA, Curtin SJ, Dedic-Hagan J, Ellacott GA, Watson JM, Wang MB, Brosnan C, Carroll BJ, et al. RNA interference-inducing hairpin RNAs in plants act through the viral defence pathway. EMBO Rep. 2006; 7:1168-1175. [PubMed: 17039251]

55. Du QS, Duan CG, Zhang ZH, Fang YY, Fang RX, Xie Q, Guo HS. DCL4 targets Cucumber mosaic virus satellite RNA at novel secondary structures. J Virol. 2007; 81:9142-9151. [PubMed: 17609283]

56. Diaz-Pendon JA, Ding SW. Direct and indirect roles of viral suppressors of RNA silencing in pathogenesis. Annu Rev Phytopathol. 2008; 46:303-326. [PubMed: 18680427]

57. Lau NC, Robine N, Martin R, Chung WJ, Niki Y, Berezikov E, Lai EC. Abundant primary piRNAs, endo-siRNAs, and microRNAs in a Drosophila ovary cell line. Genome Res. 2009; 19:1776-1785. [PubMed: 19541914]

58. Saito K, Inagaki S, Mituyama T, Kawamura Y, Ono Y, Sakota E, Kotani H, Asai K, Siomi H, Siomi MC. A regulatory circuit for piwi by the large Maf gene traffic jam in Drosophila. Nature. 2009; 461:1296-1299. [PubMed: 19812547]

59*. Scott JC, Brackney DE, Campbell CL, Bondu-Hawkins V, Hjelle B, Ebel GD, Olson KE, Blair CD. Comparison of dengue virus type 2-specific small RNAs from RNA interference-competent and -incompetent mosquito cells. PLoS Negl Trop Dis. 2010; 4:e848. This paper reports production of piRNA-like viral small RNAs in a mosquito cell line defective in RNAi. [PubMed: 21049014] 
60. Brackney DE, Scott JC, Sagawa F, Woodward JE, Miller NA, Schilkey FD, Mudge J, Wilusz J, Olson KE, Blair CD, et al. C6/36 Aedes albopictus cells have a dysfunctional antiviral RNA interference response. PLoS Neg1 Trop Dis. 2010; 4:e856. [PubMed: 21049065]

61. Chotkowski HL, Ciota AT, Jia Y, Puig-Basagoiti F, Kramer LD, Shi PY, Glaser RL. West Nile virus infection of Drosophila melanogaster induces a protective RNAi response. Virology. 2008; 377:197-206. [PubMed: 18501400]

62. Zambon RA, Vakharia VN, Wu LP. RNAi is an antiviral immune response against a dsRNA virus in Drosophila melanogaster. Cell Microbiol. 2006; 8:880-889. [PubMed: 16611236]

63. Mims CA. Vertical transmission of viruses. Microbiol Rev. 1981; 45:267-286. [PubMed: 6790919]

64. Allen E, Xie Z, Gustafson AM, Carrington JC. microRNA-directed phasing during trans-acting siRNA biogenesis in plants. Cell. 2005; 121:207-221. [PubMed: 15851028]

65. Vagin VV, Sigova A, Li C, Seitz H, Gvozdev V, Zamore PD. A distinct small RNA pathway silences selfish genetic elements in the germline. Science. 2006; 313:320-324. [PubMed: 16809489]

66. Donaire L, Wang Y, Gonzalez-Ibeas D, Mayer KF, Aranda MA, Llave C. Deep-sequencing of plant viral small RNAs reveals effective and widespread targeting of viral genomes. Virology. 2009; 392:203-214. [PubMed: 19665162]

67. Vodovar N, Goic B, Blanc H, Saleh MC. In silico reconstruction of viral genomes from small RNAs improves viral-derived siRNA profiling. J Virol. 2011; 85:11016-11021. [PubMed: 21880776]

68. Hagen C, Frizzi A, Kao J, Jia L, Huang M, Zhang Y, Huang S. Using small RNA sequences to diagnose, sequence, and investigate the infectivity characteristics of vegetable-infecting viruses. Arch Virol. 2011; 156:1209-1216. [PubMed: 21448740]

69. Kreuze JF, Perez A, Untiveros M, Quispe D, Fuentes S, Barker I, Simon R. Complete viral genome sequence and discovery of novel viruses by deep sequencing of small RNAs: a generic method for diagnosis, discovery and sequencing of viruses. Virology. 2009; 388:1-7. [PubMed: 19394993]

70. Lipkin WI. Microbe hunting. Microbiol Mol Biol Rev. 2010; 74:363-377. [PubMed: 20805403]

71. Wang XH, Aliyari R, Li WX, Li HW, Kim K, Carthew R, Atkinson P, Ding SW. RNA interference directs innate immunity against viruses in adult Drosophila. Science. 2006; 312:452454. [PubMed: 16556799]

72. Lemaitre B, Nicolas E, Michaut L, Reichhart JM, Hoffmann JA. The dorsoventral regulatory gene cassette spatzle/Toll/cactus controls the potent antifungal response in Drosophila adults. Cell. 1996; 86:973-983. [PubMed: 8808632]

73. Ding SW, Voinnet O. Antiviral immunity directed by small RNAs. Cell. 2007; 130:413-426. [PubMed: 17693253]

74. Machlin ES, Sarnow P, Sagan SM. Masking the 5' terminal nucleotides of the hepatitis C virus genome by an unconventional microRNA-target RNA complex. Proc Natl Acad Sci U S A. 2011; 108:3193-3198. [PubMed: 21220300]

75. Drinnenberg IA, Fink GR, Bartel DP. Compatibility with killer explains the rise of RNAi-deficient fungi. Science. 2011; 333:1592. [PubMed: 21921191] 


\section{Highlights}

- RNA-based antiviral immunity increases the extrinsic incubation period required for virus transmission by mosquitoes, and is sufficiently potent to terminal infection but independent of the Toll and Imd signaling pathways essential for bacterial and fungal immunity in adult Drosophila

- Discovery of natural viral pathogens of C. elegans establishes a new small animal model for innate immunity studies

- Functional expansion and specialization of gene families in RNA-based antiviral immunity occur in plants

- Viral disease symptoms can be caused by specific silencing of an important host gene guided by a pathogen-derived siRNA

- Virus-derived small RNAs are produced in mammalian cells infected with hepatitis $\mathrm{C}$ and influenza A viruses, but it remains unclear if the RNAi pathway has a natural antiviral role in mammals

- Virus-derived piRNAs are produced in infected fruit fly and mosquito cells, but it is unclear if there is an antiviral function for viral piRNAs and/or the piRNA pathway, which is highly conserved between insects and mammals

- A novel culture-independent approach for virus discovery has been established by deep sequencing and assembly of virus-derived siRNAs and piRNAs. 


\section{Viral genomic RNA}

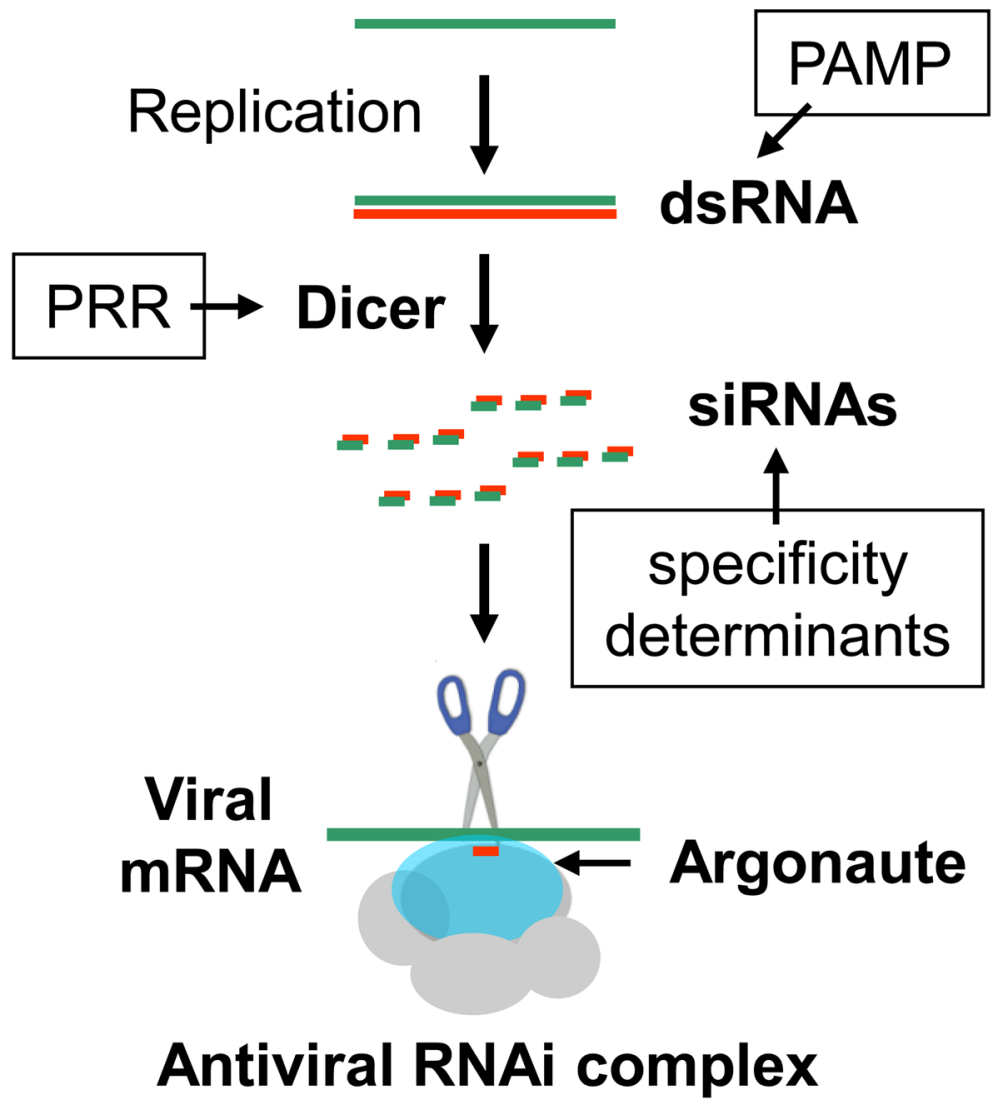

Fig. 1.

Innate \& adaptive properties of RNA-based antiviral immunity. Infection of RNA viruses in fungi, plants, insects and mosquitoes triggers biogenesis of virus-derived siRNAs, which are then assembled with an Argonaute protein and others into an effector complex to guide specific clearance of viral RNAs in the infected cell. Effective antiviral immunity in plants also depends on the amplification of viral siRNAs by host RNA-dependent RNA polymerase (not shown). Recognition of pathogen-associated molecular patterns (PAMP) by pattern recognition receptors (PRR) in Drosophila and mammalian innate immunity resembles the detection of the viral dsRNA by the Dicer nuclease except that the latter generates pathogen-derived siRNAs, which are used as specificity determinants in a manner analogous to the mammalian adaptive immunity. 
A
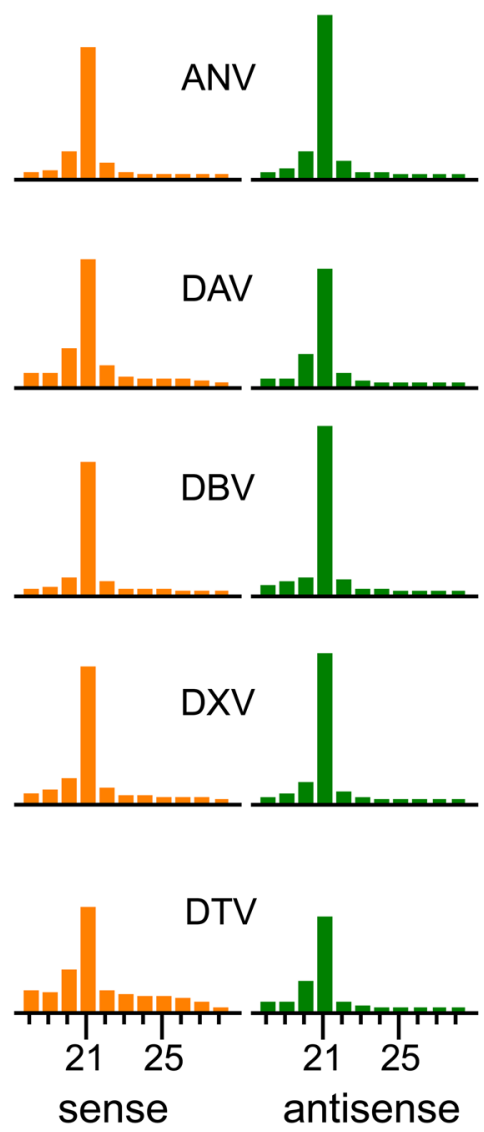

B
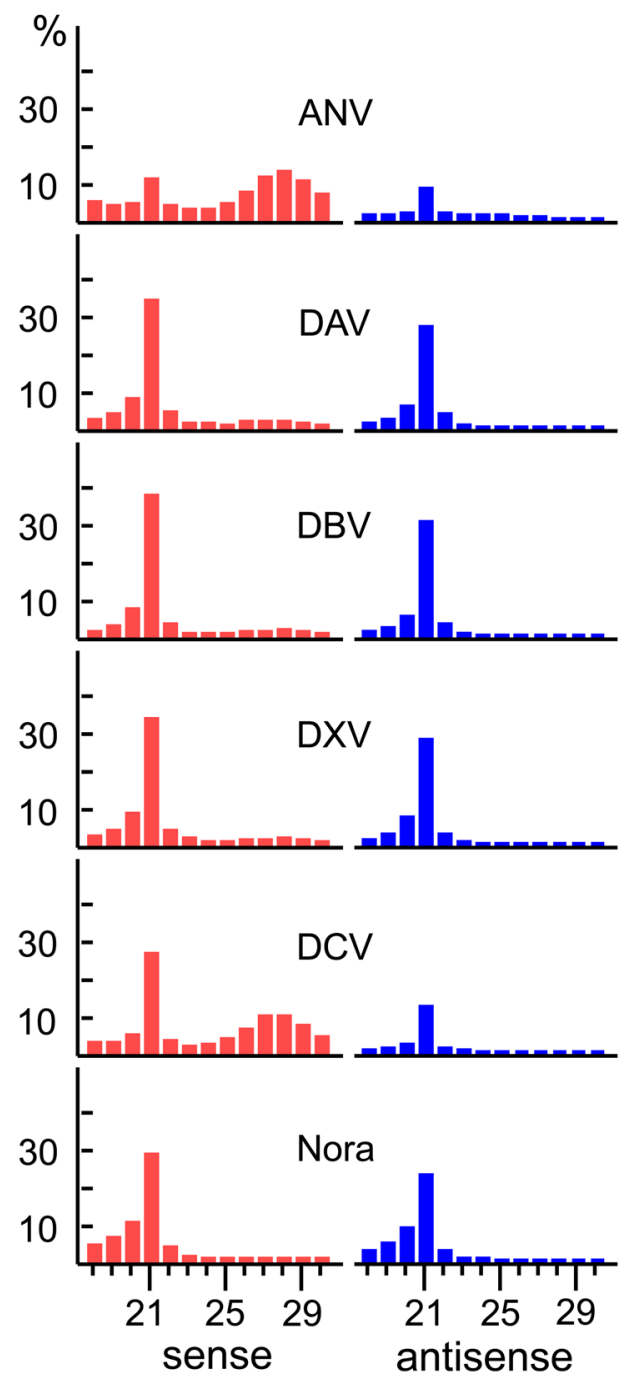

Figure 2, A\&B 


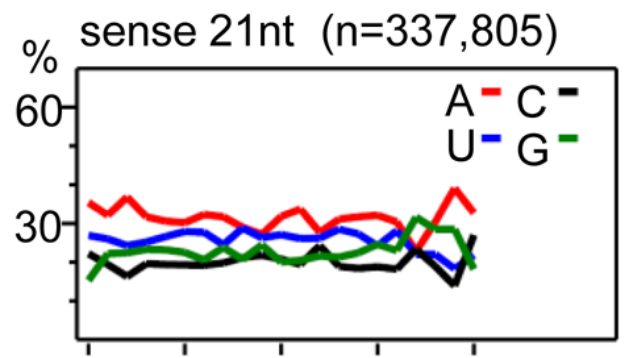

sense $27-28 n t(n=105,794)$
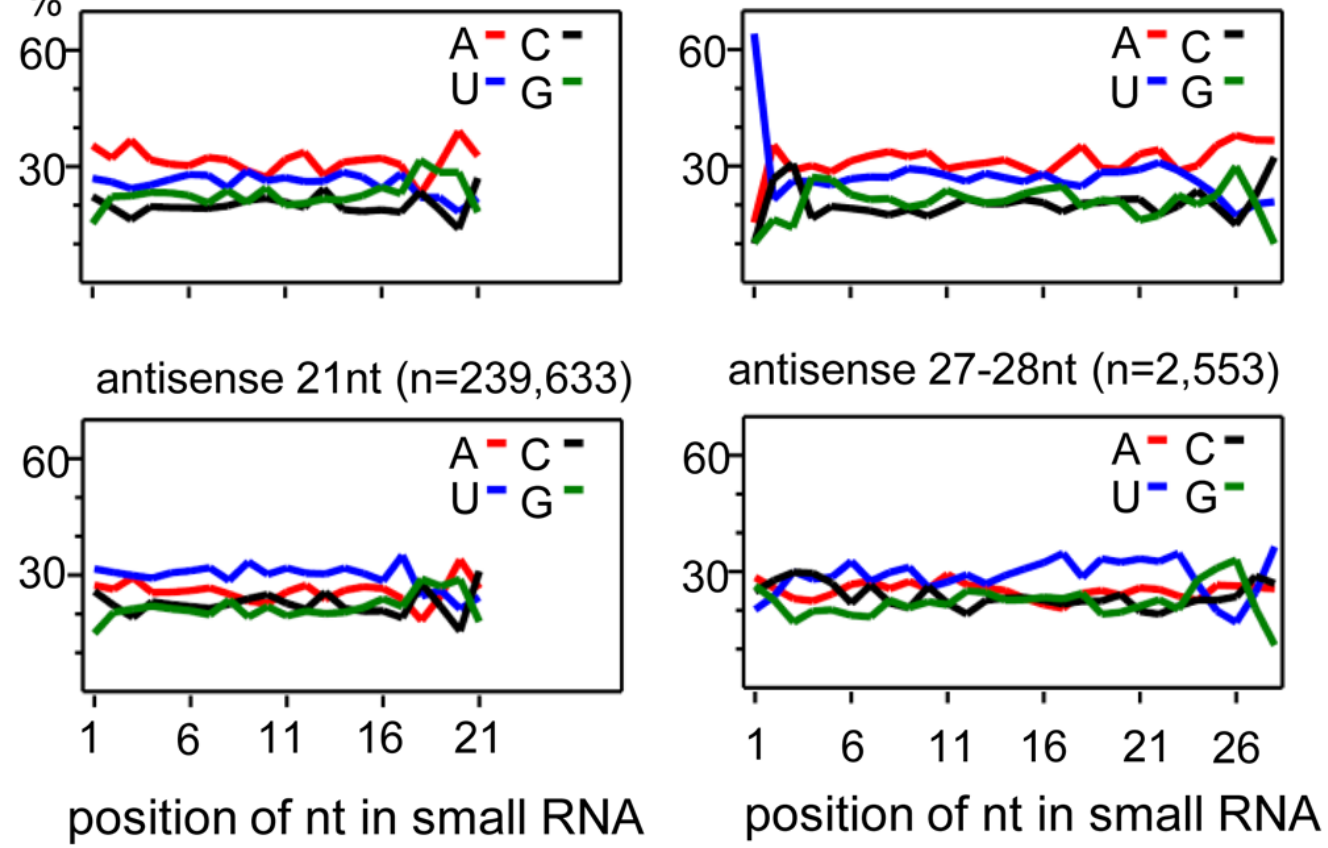

\section{Figure 2C}

Fig. 2.

Properties of viral siRNAs and piRNAs from Drosophila. A \& B. Distribution of sense and antisense viral siRNAs and piRNAs cloned respectively from Drosophila S2 cells and ovary somatic sheet cells and sequenced by the Illumina platform. The persistently infected viruses include four with +RNA genomes (ANV, DAV, DCV and Nora virus) and three with dsRNA genomes (DBV, DXV and DTV). C. Aggregate nucleotide composition of total sense and antisense 21nt viral siRNAs and 27-28nt viral piRNAs cloned from Drosophila ovary somatic sheet cells persistently infected with the six RNA viruses. Note that the strong 5 '-terminal uridine bias is observed for the +-strand piRNAs only. 
A

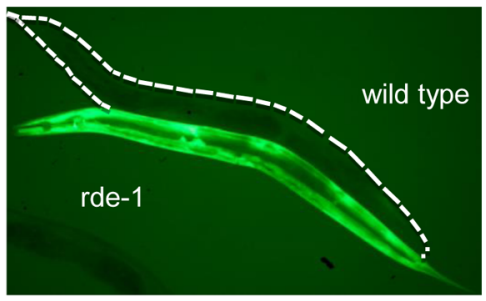

C

Viral siRNAs cloned from FR1gfp/rde-1 worms

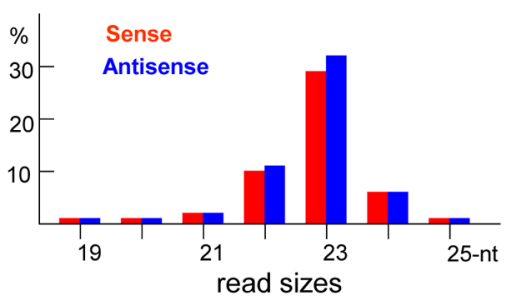

B

FHV RNA1 (3107 nt)

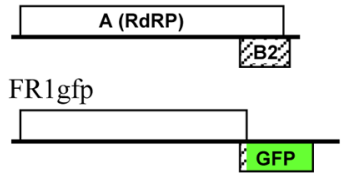

D

CARDs DEAD-box CTD

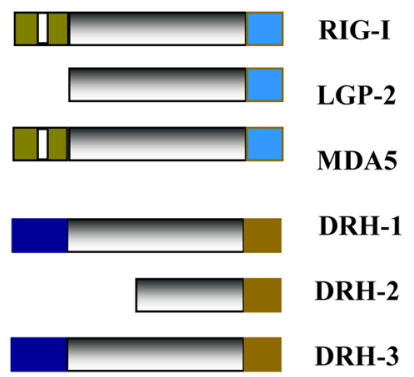

Fig. 3.

RNA-based antiviral immunity in Caenorhabditis elegans. A. A loss of function allele of rde-1 restored GFP expression from an FHV-based replicon, FR1gfp, whose replication is suppressed in wild-type worms. B. Genome structure of FHV RNA1 and FR1gfp. FHV RNA1 encodes protein A, the catalytic subunit of the viral RdRP which also directs transcription of RNA3, the mRNA for VSR protein B2. FR1gfp was created by replacing the majority of B2 coding sequence with that of GFP such that the GFP was produced as a fusion protein with the $\mathrm{N}$ terminus of B2. C. Size distribution of sense and antisense viral siRNAs cloned from $r d e-1$ null mutants. RDE- 1 is an AGO required for the biogenesis of secondary siRNAs in RNAi induced by exogenous dsRNA. D. The helicase domains of three DRH proteins are highly homologous to those of the RIG-I family of human immune receptors. CARD, caspase activation and recruitment domain; DEAD-box, the DExD/H-box helicase domain; CTD, C terminal regulatory domain. Note: DRH-1 and DRH-3 also feature an $\mathrm{N}$ terminal domain (in blue) with currently unknown function. 
A

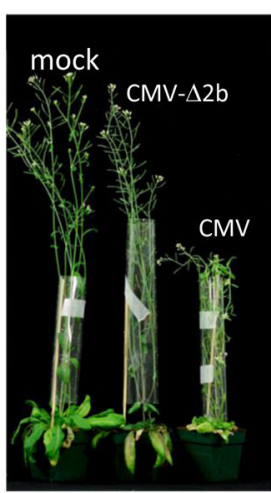

Col-0 plants

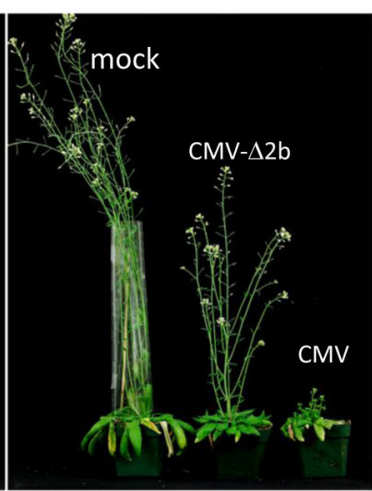

rdr1/6 plants

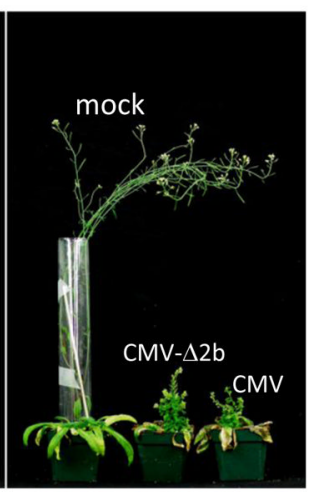

dcl2/4 plants

B
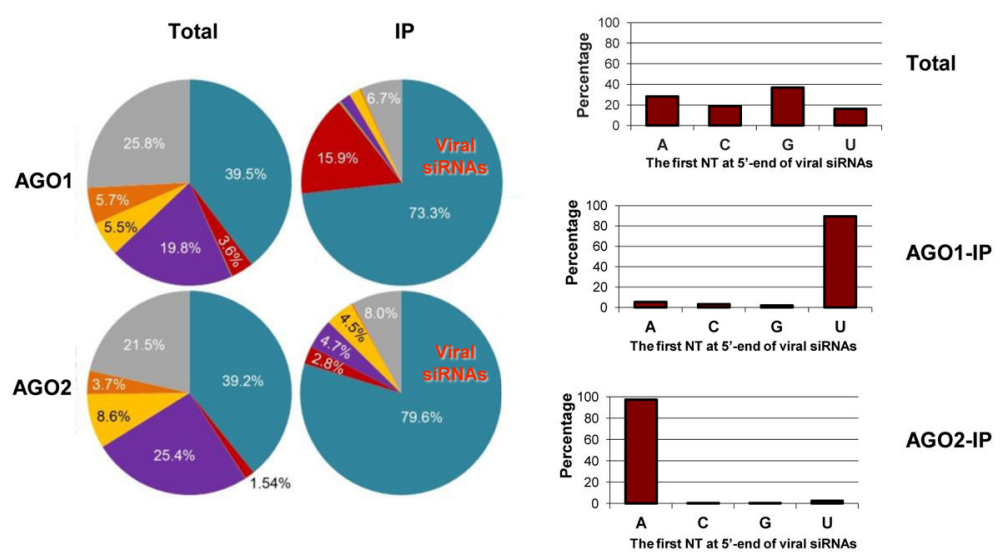

AGO2-IP

Fig. 4.

Antiviral immunity directed by viral primary and secondary siRNAs in Arabidopsis thaliana. A. Distinct virulence phenotypes of cucumber mosaic virus (CMV) and its VSRdeficient mutant (CMV- $\Delta 2$ b) six weeks post infection in wild-type (Col-0) and mutant plants as indicated. In the absence of viral suppression of RNA silencing, CMV- $\triangle 2 \mathrm{~b}$ is avirulent in wild-type plants, but becomes as virulent as CMV in DCL2 and DCLA double knockout plants (dcl2/4), which produce neither primary nor secondary viral siRNAs. The viral primary siRNAs processed from viral RdRP products in RDRI and RDR6 double knockout plants (rdr1/6) provide a basal defense so that virulence of CMV- $\Delta 2 \mathrm{~b}$ is only partially rescued. B. Selective enrichment of viral siRNAs in AGO1 and AGO2. Left panel, relative abundance of different categories of small RNAs obtained and deep sequenced from plants infected with CMV- $\Delta 2 \mathrm{~b}$ before and after co-immunoprecipitation (IP) with AGO1 or AGO2. Right panel, properties of viral siRNAs loaded in AGO1 and AGO2 sequenced from plants infected with CMV- $\Delta 2 \mathrm{~b}$. 


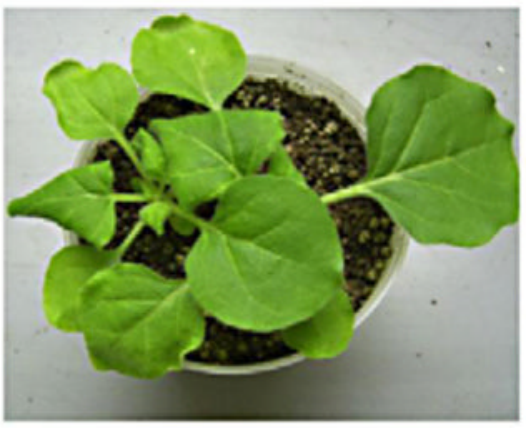

CMV+Y-sat mut-Tom

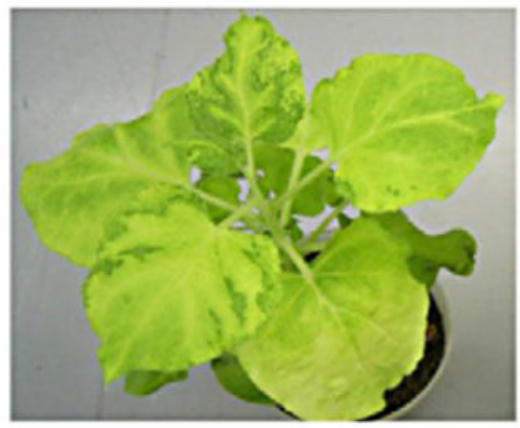

CMV+Y-sat

Fig. 5.

Disease symptom induction by an siRNA derived from Y satellite RNA (Y-sat) of Cucumber mosaic virus (CMV). Shown are $N$. benthamiana plants 14 days post infection by CMV together with Y-sat or Y-sat mut-Tom at as indicated. Y-sat mut-Tom is a Y-sat mutant that contains two point mutations to disrupt a highly complementary region of 22 nucleotides between Y-sat and a host mRNA, which encodes a key protein involved in chlorophyll synthesis. Reprinted with the authors' permission from ref 52. 
A

Small RNA reads

Assembly

Small RNA contigs

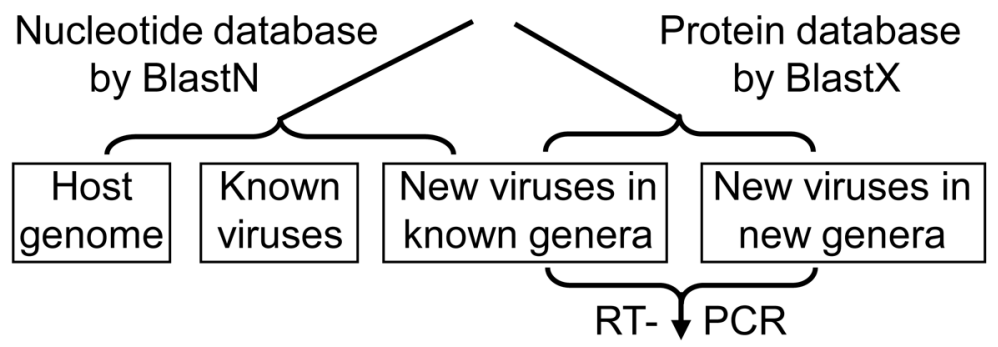

Complete

viral genomes

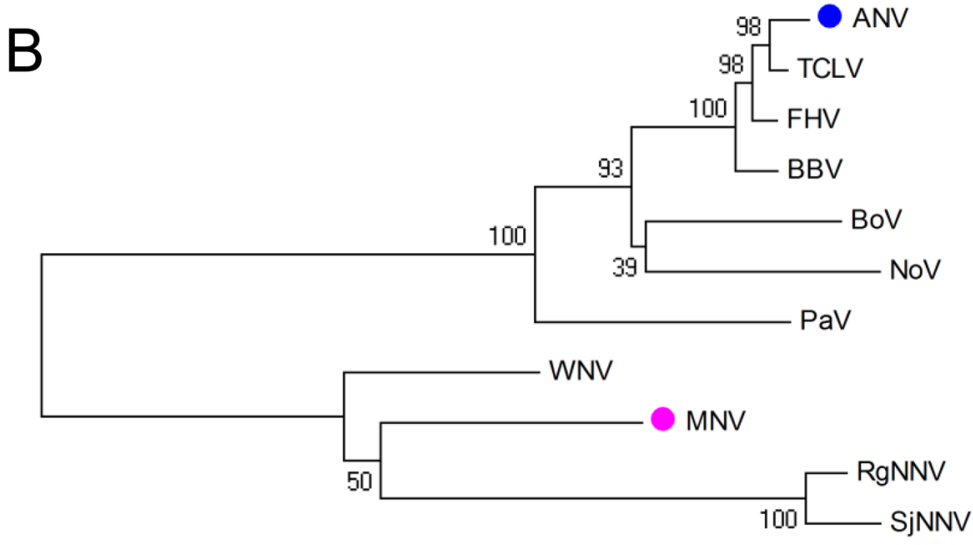

0.2

Fig. 6.

Virus discovery through deep sequencing and assembly of vsRNAs A. Work flow of virus discovery by deep sequencing and assembly of virus-derived small RNAs. B. Phylogenetic analysis of the two new nodaviruses using the Clustal $\mathrm{W}$ method. The viral CP sequences were used as input for this analysis. Abbreviations of virus names are as follows: ANV, American nodavirus; TCLV, Tn5 cell line virus; FHV, Flock house virus; BBV, Black bettle virus; BoV, Boolarra virus; NoV, Nodamura virus; PaV, Pariacato virus; WNV, Wuhan nodavirus; MNV, Mosquito nodavirus; RgNNV, Redspotted grouper nervous necrosis virus; SjNNV, Striped Jack nervous necrosis virus. 